\title{
Factors explaining the geographical differences in Disability Free Life Expectancy in Spain
}

\author{
Juan Luis Gutiérrez-Fisac, Rosa Gispert, Judit Solà
}

\begin{abstract}
Objective-To study the geographical variations in Disability Free Life Expectancy (DFLE) at birth (DFLEb) and at 65 years (DFLE65) in Spain and to identify the main factors that explain these variations. Design-Ecological study with the 50 provinces of Spain as the units of analysis. Sullivan's method is used to calculate DFLE for each province based on information from the death registry and the survey on disabilities, impairments and handicaps. Information on the independent variables-socioeconomic level, factors related with the health system and risk factors-was taken from various sources.

Main outcome measure-Simple correlation coefficients were obtained between each dependent variable (DFLEb and DLFE65) and the independent variables. Two multiple linear regression models were fit to obtain the best set of factors that explain the geographical distribution of DFLEb and DLFE65.

Results-Both DFLEb and DLFE65 vary widely among provinces. The multiple linear regression analysis shows that the illiteracy rate, the percentage of the unemployed and the percentage of smokers in the population were the main factors associated with the geographical variation of DFLE. The models explained approximately $40 \%$ of the variance for DFLEb and $30 \%$ for DLFE65.

Conclusions-The results obtained show the influence of education, the unemployment rate and smoking on the geographical differences of DFLE. The DFLE indicators are shown to be valid for use in health policy.

(F Epidemiol Community Health 2000;54:451-455)
\end{abstract}

Department of

Epidemiology,

Ministry of Health,

Madrid, Spain

J L Gutiérrez-Fisac

Institut d'Estudis de la Salut, Spain

R Gispert

Fundació Parc Taulí, Spain

$\mathrm{J}$ Solà

Correspondence to: Dr Gutiérrez-Fisac, Subdirección General de Epidemiología, Ministrio de Sanidad, Paseo del Prado 18-20, 28014 Madrid, Spain (jgutierrez@msc.es)

Accepted for publication 30 November 1999

For several decades the classic health indicators based on morbidity and mortality have been shown to be insufficient to rigorously describe, monitor and evaluate the health status and health needs of the population. As a result, a series of indicators intending to reflect population's health status more accurately have arisen including mortality as well as factors related with perceived health or the consequences of disease. One of the most widely accepted and used of these indicators today is Disability Free Life Expectancy (DFLE), ${ }^{1}$ which has also been proposed by the Regional Office for Europe of the World Health Organisation (WHO) to evaluate the strategy of Health for All. ${ }^{2}$

Since Sanders defined the indicator conceptually in $1964^{3}$ and Sullivan developed a method to calculate it, ${ }^{4}$ the DFLE has become increasingly available, and many countries currently have reasonable estimates of the indicator. The fact that DFLE combines data on mortality and disability and that it is relatively easy to calculate has made it one of the main candidates for routine use in different areas of health policy, such as monitoring and evaluating the health status of the population, studying health inequalities among different population groups or allocating resources in the short-term. ${ }^{5}$

In health policy, one factor that favours the use of health indicators in general, and of DFLE in particular, is that they can be used to obtain estimates broken down by different variables of interest, such as socioeconomic level or geographical distribution. To date, few countries have been able to obtain such estimates. ${ }^{6}$

The possible geographical differences among areas within a country are of great interest in public health and health policy as they show the potential for prevention that still exists. The finding of north-south differences in a country, for example, should suggest consideration of what factors affecting such variations can be modified. Thus, the study of the major variables and factors that determine these geographical differences is a matter of great interest because it helps to provide rational guidance on possible activities to reduce such differences and, in short, to increase the level of health in the whole population.

Few studies have investigated the factors that explain such variations. To our knowledge, only one study in England has analysed the factors involved in regional variations. ${ }^{5}$ The objective of this work is to study the distribution of DFLE indicators among provinces in Spain and to analyse the main factors explaining this distribution.

\section{Methods}

We carried out an ecological study using the 50 provinces that make up the nation of Spain as units of analysis. The dependent study variables are DFLE at birth (DFLEb) and at 65 years of age (DFLE65).

The DFLE indicators for each province were calculated by Sullivan's method. ${ }^{4}$ The calculation is made using a life table in which death is weighted by the prevalence of disability. Information on permanent disability was taken from the survey on disabilities, impairments and handicaps that the National Institute of Statistics (INE in Spanish) carried out in $1986 .{ }^{7}$ In this survey disability was considered to be any permanent limitation of activity that lasted or was expected to last for more than one year. The survey included basic activities in accordance 

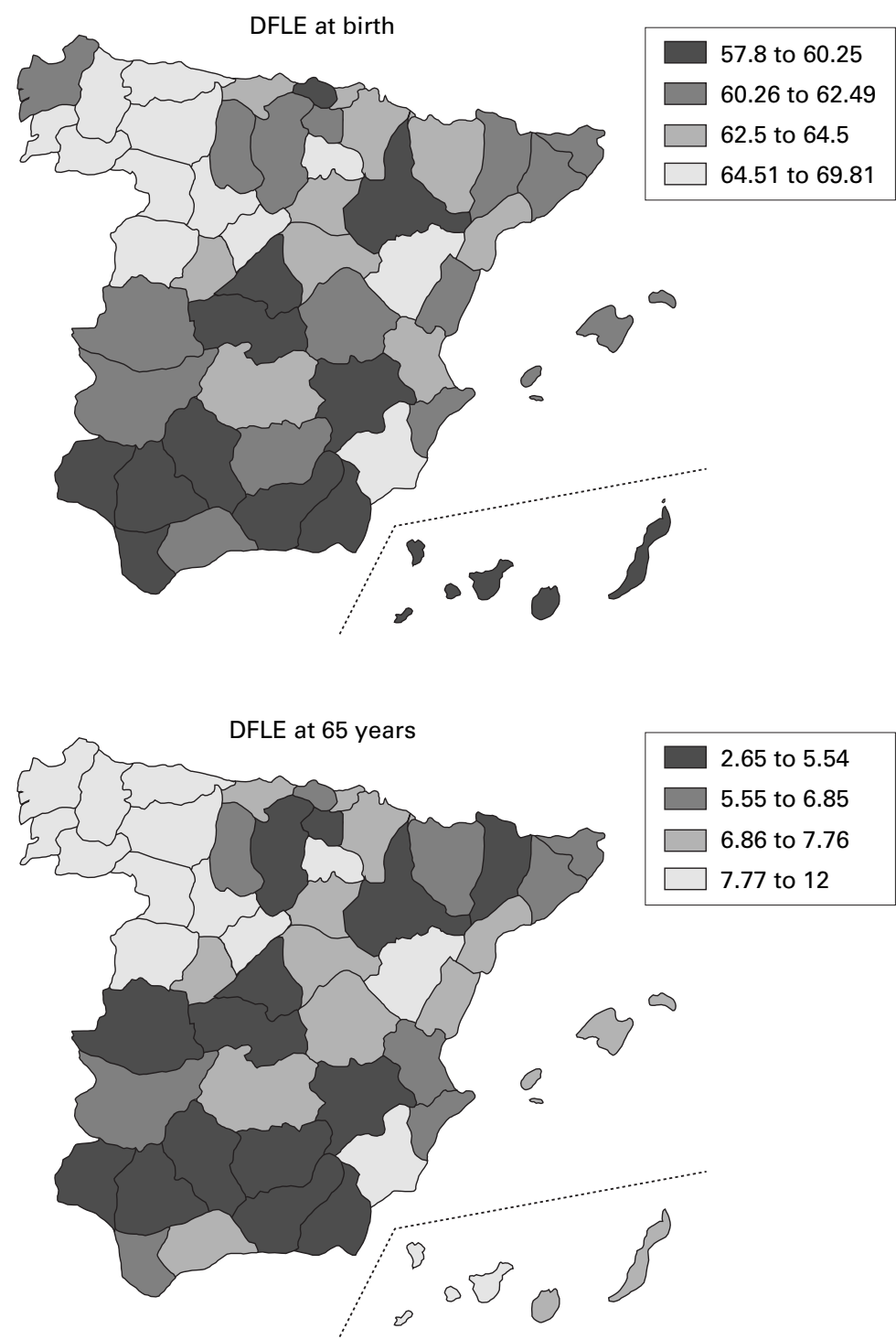

Figure 1 Geographical distribution of Disability Free Life Expectancy (DFLE) at birth and at 65 years of age. tors were obtained from the Municipal Census of the population of 1 April 1986, also published by the INE. ${ }^{10}$

The independent variables considered were socioeconomic factors, variables related with the health system and certain risk factors associated with lifestyle. The socioeconomic factors used were the illiteracy rate per 1000 population, the percentage of the unemployed population and the percentage of rural population (those living in towns with fewer than 50000 inhabitants), all of this information was obtained from the 1986 Municipal Census of the population. ${ }^{10}$ We also used the number of immigrants per 100000 population, the number of automobiles per capita and the number of telephone lines per 1000 population, information that was obtained from the Annual Statistics of the INE. ${ }^{11}$

The variables related to the health care system were the number of hospital beds per 1000 population and the mean hospital stay, both of which were obtained from the Statistics of Inpatient Health Facilities. ${ }^{12}$ We also used the number of physicians per 1000 population published in the Annual Statistics of the INE. ${ }^{11}$ The risk factors related to behaviour and lifestyle were the percentage of smokers in the population and the percentage of the population that consumes alcohol, both indicators obtained from the National Health Survey carried out by the Ministry of Health in 1987 in a representative sample of the noninstitutionalised Spanish population. ${ }^{13}$ Finally, we included as an independent variable the percentage of the population 65 years of age and older, as an indicator of a type of society.

The statistical analysis was made separately for each of the two dependent variables: DFLEb and DFLE65. Basic descriptive statistics were calculated. The quartile distribution of the main variables are presented using maps. Pearson correlation coefficients were calculated between the independent variables and each of the dependent variables. Finally, variables showing a statistically significant simple association with the dependent variable, those with a high correlation coefficient even being not significant and those other study variables of conceptual relevance for public health purposes were used to fit a multiple linear regression model for each of the dependent

Table 1 Descriptive statistics and correlation coefficients of variables included in the study

\begin{tabular}{lrrrrr}
\hline & & & & \multicolumn{2}{c}{ Correlation coefficient } \\
\cline { 4 - 6 } & Mean & Maximun & Minimun & DFLE at birth & DFLE at 65 \\
\hline DFLE† at birth & 62.5 & 69.8 & 57.8 & 1.000 & $0.893^{\star}$ \\
DFLE at 65 & 7.1 & 12.0 & 2.65 & $0.893^{\star}$ & 1.000 \\
Illiteracy (per 1000 pop) & 40.4 & 105.1 & 6.0 & $-0.471^{\star \star}$ & $-0.381^{\star \star}$ \\
Unemployment rate (\%) & 19.8 & 39.5 & 8.8 & $-0.564^{\star \star}$ & $-0.453^{\star \star}$ \\
Rural population (\%) of pop) & 61.3 & 100.0 & 11.8 & 0.200 & 0.125 \\
Phone lines (per 1000 pop) & 219.7 & 355.9 & 129.1 & 0.109 & 0.011 \\
Inmigrant (per 100 000 pop) & 27.9 & 105.9 & 0.9 & -0.084 & -0.049 \\
Cars (per capita) & 0.3 & 1.0 & 0.1 & -0.157 & -0.085 \\
Average length of stay (in hospitals) & 14.5 & 39.6 & 8.9 & 0.234 & 0.219 \\
Beds (per 1000 pop) & 4.6 & 10.9 & 2.2 & 0.215 & 0.159 \\
Doctors (per 1000 pop) & 3.2 & 5.1 & 2.1 & $0.281^{\star}$ & 0.183 \\
Alcohol consumption (\% of pop) & 10.9 & 25.4 & 2.5 & -0.129 & -0.256 \\
Smoking (\% of pop) & 37.5 & 45.6 & 29.9 & -0.265 & $-0.283^{\star}$ \\
Age >65 (\% of pop) & 13.6 & 20.0 & 7.8 & $0.540^{\star \star}$ & $0.389^{\star \star}$
\end{tabular}

†DFLE: Disability free life expectancy. ${ }^{\star} \mathrm{p}<0.05,{ }^{\star \star} \mathrm{p}<0.01$. 

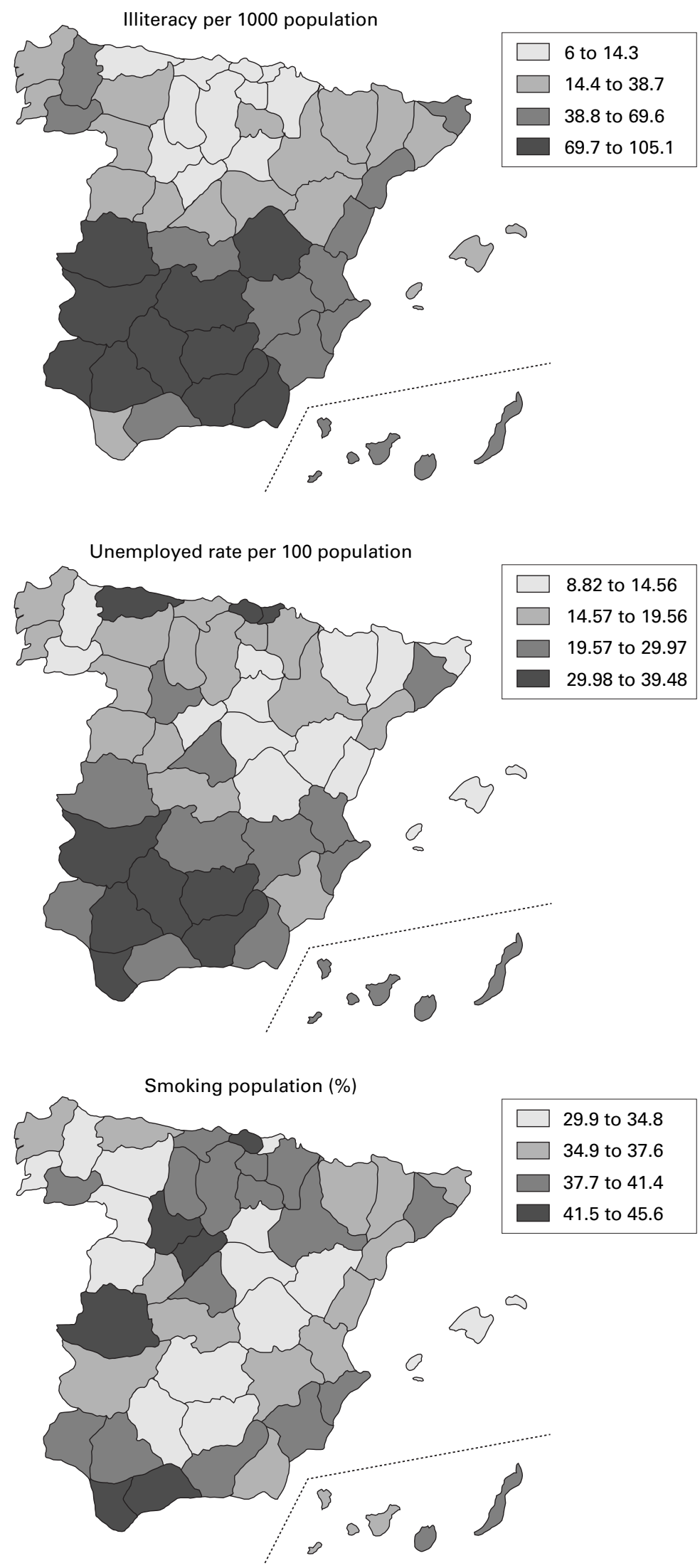

Figure 2 Geographical distribution of illiteracy per 1000 population, unemployment rate per 100 population and smoking population (\%).

variables, to obtain the model that included the variables that best explain the geographical distribution of DFLE.
KEY POINTS

- Disability Free Life Expectancy (DFLE) indicators show large variations among Spanish provinces, with a north-south and east-west geographical pattern.

- Geographical differences in DFLE indicators are mainly explained by educational level, unemployment rate and smoking.

- The results obtained support the DFLE indicator's validity as a reflection of the health status of the population.

- DFLE indicators can play an important part in several areas of health policy, such as monitoring the health of the population, studying health inequalities and their trends over time and establishing the health needs of the population.

The calculations and statistical analyses were made using the statistical package SPSS. ${ }^{14}$

\section{Results}

The descriptive analysis of the data shows large variations in the geographical distribution of DFLE. In figure 1 it can be observed that an area in the south and west of Spain has the lowest indices of DFLE - both DFLEb and EFLE65-which may be defining a northsouth and east-west gradient. This large variation can also be seen in table 1 , where a difference of 12 years can be seen between the provinces with the highest and lowest DFLEb. In the case of DFLE65 the difference is more than nine years.

Table 1 also shows large variations among Spanish provinces for most of the variables included in the study. Especially notable are the large differences seen in the illiteracy rate, the unemployment rate and the percentage of smokers in the population. Figure 2 shows the geographical distribution of these three variables.

The simple correlation analysis shows several variables that are significantly associated with DFLE. Besides the percentage of population 65 years and older, the illiteracy and unemployment rates and the number of physicians per 1000 population had statistically significant correlation coefficients with DFLEb. In the case of DFLE65, the percentage of smokers also showed a statistically significant correlation coefficient. Other variables such as the percentage of rural population, mean duration of hospital stay, number of beds per 1000 population or alcohol consumption had rather high correlation coefficients $(>0.30)$, but these did not reach statistical significance.

Table 2 shows the final results of the multiple regression analysis made on the dependent variables, in which we initially included the independent variables that had shown a statistically significant association or a high correlation coefficient in the simple analysis. As can be seen, in the case of DFLEb, the illiteracy rate, unemployment rate and percentage of smokers were finally selected in the model, which explained slightly more than $40 \%$ of the 
Table 2 Linear regression models of $D F L E^{\star}$ at birth and at 65 years of age

\begin{tabular}{llllll}
\hline & $\beta$ & $S E$ & Standardised $\beta$ & $p$ & $r^{2}$ \\
\hline $\begin{array}{lllll}\text { DFLE at birth } \\
\quad \text { Illiteracy }\end{array}$ & -0.038 & 0.015 & -0.373 & 0.011 & 0.415 \\
$\quad$ Unemployment rate & -0.113 & 0.053 & -0.310 & 0.039 & \\
$\quad$ Smoking & -0.178 & 0.096 & -0.243 & 0.070 & \\
DFLE at 65 & -0.035 & 0.010 & -0.457 & 0.001 & 0.280 \\
$\quad$ Illiteracy & -0.206 & 0.069 & -0.375 & 0.005 & \\
$\quad$ Smoking & & & & \\
\hline
\end{tabular}

^DFLE: Disability Free Life Expectancy.

geographical variation in DFLEb. Illiteracy was the variable that most influenced the geographical distribution of DFLEb. The association is negative for all three variables included in the model, that is, DFLEb decreases with increasing unemployment rate, illiteracy rate and percentage of smokers in the population.

In the case of DFLE65, the model that includes illiteracy and the percentage of smokers in the population explains about $30 \%$ of the variation. The variable with the most influence on the geographical distribution of DFLE65 was the illiteracy rate. Smoking showed a larger influence on the geographical distribution of DFLE65 than DFLEb, both in terms of the magnitude of the regression coefficient and statistical significance.

\section{Discussion}

The results of this study highlight two important facts. Firstly, the DFLE indicators show large variations among provinces in Spain, with a north-south and east-west geographical pattern. Secondly, these differences are mainly explained by level of education, unemployment and smoking.

The few studies that have looked at geographical differences in DFLE have yielded results showing large variations in this indicator. In Canada there were differences of more than three years in DFLE among the country's five regions. ${ }^{15}$ In Australia, ${ }^{16}$ the differences were larger: up to eight years in DFLEb in women, and almost three years in DFLE65 among the eight regions of the country. Using data from Great Britain, Bebbington also demonstrates how widely the indicator varies among the 10 regions studied, with differences of about five and two years in DFLEb and DFLE65, respectively. ${ }^{17}$ These differences are smaller than those observed in the present work in Spain. The larger number of geographical units of analysis in Spain (50 provinces) may produce the effect of a greater magnitude in the differences. In fact, in England, when geographical differences in DFLE are studied by local authority area, the differences are much greater than when they are analysed by health authorities. ${ }^{5}$ It is also possible that in Spain - a country with a lower level of socioeconomic development than Canada, Australia or Great Britain - the differences and inequalities by place of residence are larger than in these other countries.

Regardless of the magnitude of the differences, the consistent geographical variation in DFLE can be interpreted from the perspective of the indicator's validity for monitoring population health, and from the point of view of the practical utility of DFLE indicators in public health. One of the commonly accepted criteria for evaluating the validity of health indicators is that they should show some variation in accordance with the main variables of epidemiological interest, of which geographical area is one. ${ }^{18}$ Thus, the variations observed among the Spanish provinces can be interpreted as showing the goodness of the indicator in reflecting the health status of different populations in the country and in capturing the differences among them. One of the most attractive uses of DFLE is for geographical comparisons, although major obstacles remain in making rigorous comparisons at the international level. ${ }^{19}$ However, these problems do not exist within a single country such as Spain, where the disability measures are obtained from the same study, and comparisons among geographical regions are less likely to present any information bias.

The results obtained by multiple linear regression analysis show that the most important explanatory factor for the provincial differences in DFLE is the illiteracy rate. The unemployment rate also had an important effect on the geographical distribution of DFLEb. Both of these factors show that social and economic circumstances are more important determinants of health differences among populations than other factors related, for example, with the availability of health resources.

Besides this study, the factors that explain geographical differences in indicators of healthy life expectancy were studied using data from England and Wales. ${ }^{5}$ The results showed that social class, unemployment rate, retirement migration and the percentage of nonwhite population were the main variables implicated in the differences. Thus, the results are similar to those found in this study, especially with regard to unemployment rate and social class (educational level in this study). The immigrant population did not show any effect on the geographical distribution of DFLE in Spain. The reason for the small explanatory power may be that Spain has a shorter history of taking in immigrant populations, or perhaps the effect of the immigrant population, visible in the simple analysis, was absorbed by variables with larger explanatory power, such as illiteracy and unemployment.

SES has been shown, by cross sectional, longitudinal and ecological studies as one of the main determinants of health. ${ }^{20-24}$ Although there is not much evidence of this association in the case of DFLE, all studies that have investigated this matter in Finland, ${ }^{25}$ the United States, ${ }^{26}$ Holland, ${ }^{27}$ Canada ${ }^{15}$ or Great Britain, ${ }^{17}$ have shown that people with lower educational level have lower DFLE. The fact that we also found this same association at the ecological level of analysis shows that possibilities for intervention exist, suggesting that modifying the educational level or the unemployment rate in the population may translate into changes in DFLE.

Another important finding of this study is the strong influence of smoking on the geographical distribution of DFLE at 65 years of age. 
Recently, a longitudinal study in the United States has shown that people with a lower level of exposure to risk factors, including tobacco consumption, have less disability over their lifetime and that the age at which disability appears, when it does occur, is later. ${ }^{28}$ Ferrucci et al have also shown that not smoking is powerful predictor of a long and healthy life. ${ }^{29}$

DFLE has been proposed as an appropriate indicator for the short-term allocation of social and health resources. ${ }^{15}$ The fact that it is associated with certain health resource indicators (such as the number of physicians per 1000 population), but at the same time is independent of them when controlling for other health related factors such as SES and risk factors linked with lifestyle, may indicate that DFLE is a measure of social and health needs in the population that is independent of resources and the use of social and health services. This makes it an optimum indicator for allocating resources. It has been mentioned that, given the extremely high correlation between indicators of DFLE and mortality, the latter would still be valid when making decisions about algorithms for distributing resources. However, the differences from region to region are larger when we use DFLE than when we use mortality alone, ${ }^{5}{ }^{30}$ therefore social and health resources would be allocated more equitably among different geographical areas if they were based on indicators that take into consideration not only the length of life, but also the level of morbidity or disability.

The results of this work should be viewed with caution. One limitation is the ecological nature of the investigation. However, the objective of this study is neither to draw conclusions about the factors determining the health of people, nor to establish causal associations about population health and the factors that determine it, but to identify the factors involved in the regional differences of DFLE. From this population perspective, it seems that ecological studies would be the most appropriate type of study, as they would try to establish relations at the population level, which is the arena for public health action.

The institutionalised population was excluded from the disability estimates. This may have modified the results obtained. However, assuming that regions with greater disability would have larger institutionalised populations than those with a lower prevalence of disability, even larger differences would have been found if we had included the institutionalised population. Thus, the possible bias derived from excluding the institutionalised population would have had the effect of reducing these differences, but would never have artificially increased them.

In conclusion, the factors that explain the geographical distribution of DFLE in Spainsocioeconomic level (illiteracy and unemployment) and smoking - support the indicator's validity as a reflection of the health status of the population. DFLE indicators can play an important part in several areas of health policy, such as monitoring the health of the population, studying health inequalities and their trends over time and establishing the health needs of the population. Consolidation of the DFLE indicator in these areas will depend on both routine availability of information and its acceptance by those responsible for health policy. Ever more consistent evidence continues to emerge of this indicator's ability to reflect the health of the population.

The authors would like to express their thanks to Montse Rué for her kind collaboration in the early stages of the project.

Funding: this work was financed by the Fondo de Investigación Sanitaria (exp 971127) of the Ministry of Health and Consumer Affairs.

Conflicts of interest: none.

1 Robine JM, Ritchie K. Healthy life expectancy: evaluation of global indicator of change in population health. $B M \mathcal{F}$ global indicator

2 WHO. Regional Office for Europe. Targets for health for all. Copenhague: WHO, 1985.

3 Sanders BS. Measuring community health levels. Am f Public Health 1964;54:1063-70.

4 Sillivan DF. A single index of mortality and morbidity. HSMHA Health Rep 1971;86:347-54.

5 Bone MR, Bebbington AC, Jagger C, et al. G. Health expectancy and its uses. London: OPCS, 1995.

6 REVES. Health Expectancies in OECD countries. Montpellier: Reves paper no 317, 1998.

7 Instituto Nacional de Estadística. Encuesta sobre discapacidades, deficiencias y minusvalías 1986. Madrid: Instituto Nacional de Estadística, 1987.

8 World Health Organization. International classification of impairments, disabilities and handicaps: a manual of classification relating to the consecuences of disease. Geneva: WHO, 1980.

9 Instituto Nacional de Estadística. Movimiento Natural de la Población Española 1986. Madrid: INE, 1988.

10 Instituto Nacional de Estadística. Padrón Municipal de HabInstituto Nacional de Estadística.
itantes 1986. Madrid: INE, 1989.

11 Instituto Nacional de Estadística. Anuario estadístico de España 1988. Madrid: INE, 1988.

12 Instituto Nacional de Estadística. Estadística de Establecimientos en Régimen de internado 1986. Madrid: INE, 1988.

3 Ministerio de Sanidad. Encuesta Nacional de Salud 1987 Madrid: Ministerio de Sanidad, 1989.

14 Norusis MJ. SPSS/PC+. Advanced statistics 4.0. Chicago: SPSS, 1990

15 Wilkins R, Adams O. Health expectancy in Canada, late 1970s: demographic, regional and social dimensions. Am f Public Health 1983;73:1073-80.

16 Mathers CD. Health expectancies in Australia 1981 and 1988. Canberra, ACT. Australian Institute of Health Publications, 1991 .

17 Bebbington AC. Regional and social variations in disabilityfree life expectancy in Great Britain. In: Robine J-M, free life expectancy in Great Britain. In: Robine J-M,
Mathers CD, Bone MR, et al, eds. Calculation of health expectancies: harmonization, consensus achieved and future perspectives. Montpellier: Colloque INSERM/John Libbey perspectives. Montpellier: Colloque
Eurotext Ltd, 1993;226:175-191.

18 Cohen MM, McWilliam L. Measuring the health of the population. Med Care 1995;33:DS21-42.

19 Gispert R, Gutiérrez-Fisac JL. Esperanza de Vida Libre de Incapacidad: pasado y presente de un indicador con futuro. Revisiones Salud Pública 1997;5:7-32.

20 Feinstein JS. The relation between socio-economic status and health: a review of the literature. Milbank $Q$ 1993;71:279-322.

21 Morris JN. Inequalities in health: ten years and little further on. Lancet 1990;2:491-3.

22 Davey Smith G, Egger M. Socioeconomic differentials in welth and health. Widening inequalities in health: the legacy of the Thatcher years. BMF 1993;307:1085-6.

23 Valkonen T, Martelin T, Rimpelä A, et al. Socio-economic differences in Finland 1981-1990. Helsinki: Central Statistical Office of Finland, 1993.

24 Regidor E, Gutiérrez-Fisac JL, Rodríguez C. Increased Regidor E, Gutierrez-Fisac JL, Rodriguez C. Increased
socioeconomic differences in mortality in eight Spanish socioeconomic differences in mortality

25 Valkonen T, Shivonen A, Lahelma E. Health expectancy by level of education in Finland. Soc Sci Med 1997;44:801-8.

26 Guralnik JM, Land KC, Blazer D, et al. Educational status and active life expectancy among older blacks and whites. $N$ Engl f Med 1993;329:110-16.

27 Boshuizen HC, van de Water HPA, Perenboom RJM. Socio-economic differences in health expectancy in the Netherlands. In: Mathers AD, MacCallum J, Robine JM, eds. Advances in health expectancies. Canberra:Australian Institute of Health and Welfare, AGPS, 1994:152-9.

28 Vita AJ, Terry RB, Hubert HB, et al. Aging, health risks and cumulative disability. $N$ Engl f Med 1998;338:1035-41.

29 Ferrucci L, Izmirlian G, Leveille S, et al. Smoking, physical activity, and active life expectancy. $A m$ f Epidemiol 1999;149:645-53.

30 Gutiérrez-Fisac JL, Regidor E, Rodríguez C. Health indicators (period 1990-1991). Evaluation in Spain of European regional program Health for all. Madrid: Ministerio de Sanidad, 1993:34. 